\section{Prevalence and predisposing factors regarding intestinal parasitic infections among rural primary school pupils at Minia Governorate, Egypt}

\author{
Fatma A.A. Ibrahium \\ Faculty of Nursing, Fayoum University, Al \\ Fayoum, Egypt
}

\section{Abstract}

About 400 million school-age children are infected with roundworm, whipworm and hookworm worldwide. This study aims to assess prevalence of parasitic infections among rural primary school pupils at Minia Governorate, Egypt, and to identify relevant predisposing factors of the school and pupils to intestinal parasitic infections. A total of 264 pupils out of 1,053, aged 6-12 years, were randomly selected for parasitological investigation and the school was inspected on site for sanitary facilities and conditions of hygiene, as well as the conditions of hygiene of the pupils. The pupils were examined for ova, cysts and/or larvae of intestinal parasites using direct wet mount and formal-ether concentration techniques. Inspection of sanitary facilities and the conditions of hygiene of the school, as well pupil's conditions of hygiene, were carried out through observation checklists. Findings revealed the following intestinal parasites: Entamoeba coli (in 19.3\% of pupils), Ascaris lumbricoides (3.8\%), Hymenolepiasis nana (12.5\%), Enterobious vermicularis (5.7\%) and Giardia lamblia (12.5\%), with varying percentages between male and female pupils, and a highly statistical association between pupil sex and type of parasites $(\mathrm{P}<0.001)$. Unapproved sanitary facilities and conditions of hygiene of the school and pupils were observed. Many intestinal parasitic infections among the primary school pupils were found. Unapproved and low inventory school sanitary facilities were observed, in addition to poor conditions of hygiene of pupils which may play a crucial role in these infections. The school facilities and sanitary conditions, especially the quality of water in the toilets, should be improved. Pupils and school personnel have a real need for health education about modes of transmission and preventive methods of intestinal parasitic infections.

\section{Introduction}

Intestinal parasitic infections still constitute one of the major causes of public health problems in the world, particularly in developing countries. ${ }^{1,2}$ Helminths or worm infestations refer to worms that live as parasites in the human body and are a fundamental cause of disease associated with health and nutrition problems beyond gastrointestinal tract disturbances. $^{2}$ Globally, over 3.5 billion people are infected with intestinal worms, of whom 1.47 billion are infected with roundworm, 1.3 billion people with hookworm and 1.05 billion with whipworm. ${ }^{1}$ Intestinal parasitic infections have been a major public health problem in Palestine over the last ten years (2000-2009). Prevalence of these parasites varies from one Arabian country to another. In the Middle East, for instance, reports on intestinal parasites have shown prevalence rates of $28.7 \%$ in Yemen, 19.3-27.3\% in Iran, 12.4\% in Lebanon, 16.6-74.6\% in the Gaza Strip (Palestine), $28.5 \%$ in Jordan, $42.5 \%$ in Syria, $31.4-32.2 \%$ in Saudi Arabia, $17.0-90.4 \%$ in Sudan, $33.9 \%$ in Qatar, 31.8-37.2\% in Turkey, and 27\% in Egypt. ${ }^{3}$ There are many reasons for the difference in prevalence of infections in these countries such as geographic and socio-economic factors, climate, poverty, malnutrition, personal and community hygiene, population density, unavailability of drinking water and poor sanitary facilities.

About 400 million school-age children around the world are infected with roundworm, whipworm and hookworm. ${ }^{4}$ Intestinal parasitic infections are endemic and have been described as the greatest single worldwide cause of illness and disease. ${ }^{5-7}$ Worm infestation is a major problem in children from developing countries. Intestinal parasitic infections are most common among schoolage children and tend to be of high intensity in school-age children. ${ }^{1,6}$ The highest infection rate and worm burden were found among school children aged 5-15 years and were attributed to poor sanitation and hygiene. These infections can affect child development, educational achievement, reproductive health, and social and economic development. ${ }^{7}$ Children are among the most vulnerable to environmental threats as they are in a dynamic state of growth with their cells multiplying fast and their organ systems developing at a rapid rate. ${ }^{8}$ These parasites consume nutrients from the children they infect, thus retarding their physical development. They destroy tissues and organs, cause abdominal pain, diarrhea, intestinal obstruction, anemia, ulcers and other health problems. All of the consequences of infection can slow cognitive development and thus impair learning. It produces nutritional deficiencies and anemia in children, especially when hookworm infestation is present. ${ }^{9,10}$ Reports from the WHO and others of the international community show that
Correspondence: Fatma Abdelalim Abdel Ghany Ibrahium, Lecturer of Community Health Nursing, Faculty of Nursing, Fayoum University, University Zone, 63514 Al Fayoum, Egypt.

Tel. +20.84.6380696 - Fax: +20.84 .6334031$

E-mail: fatmasefaan@yahoo.com

Key words: intestinal parasitic infections, school sanitation, conditions of hygiene, pupil

Received for publication: 21 March 2011. Accepted for publication: 24 June 2011.

This work is licensed under a Creative Commons Attribution NonCommercial 3.0 License (CC BYNC 3.0).

(C) Copyright F.A.A.G. Ibrahium, 2011

Licensee PAGEPress, Italy

Journal of Public Health in Africa 2011; 2:e29 doi:10.4081/jphia.2011.e29

there is real potential for improving child health and creating a better future for the coming generations through scaling up action to confront environmental dangers. ${ }^{8,10,11}$ The present study was conducted to assess prevalence of intestinal parasitic infections among rural primary school pupils at Minia Governorate and to identify relevant predisposing factors of the school and pupils regarding intestinal parasitic infections.

\section{Materials and Methods}

A cross-sectional design was utilized in this study. The study was conducted in a Damaries rural primary school in Minia Governorate between mid-February 2009 to mid-May 2009 (2nd semester of the academic year 2008/2009). Minia Governorate is one of the Upper Egypt Governorates, 247 km from Cairo. The study was carried out with the permission of the school authorities. A total of 264 pupils out of 1,053 aged 6-12 years were randomly selected for parasitological investigation and the school was inspected on site to evaluate sanitary facilities and conditions of hygiene, as well as conditions of hygiene of the pupils. Additional pupils' personal data information were collected including name (code), age, sex, parents' level of education and occupation, and any physical complaints pertinent to the study of the pupil at the time of data collection. Afterwards, the randomly selected pupils were each given a clean, dry, well-labeled specimen bottle in which to deposit their fecal samples. The procedure for introducing fecal material into the bottles was explained and demonstrated to pupils by the researcher and class teachers. Fecal samples were collected and transported to the laboratory for analysis. The 
Table 1. Socio-demographic characteristics of the study sample ( $n=264$ pupils).

\begin{tabular}{lccc} 
& Variable & N & $\%$ \\
Sex & Male & 93 & 35.2 \\
Age & Female & 171 & 64.8 \\
& $\leq 6-8$ years & 63 & 23.9 \\
& $\leq 9-12$ years & 201 & 76.1 \\
\hline Father's level of education & Mean \pm SD & & $8.85 \pm 1.18$ \\
& Illiterate & 192 & 72.7 \\
& Can read and write & 0 & 0 \\
Father's work & Diploma & 72 & 27.3 \\
& University & 0 & 0 \\
\hline Mother's level of education & Manual & 212 & 80.3 \\
& Professional & 52 & 19.7 \\
& Illiterate & 218 & 81.8 \\
& Can read and write & 0 & 0 \\
Mother's work & Diploma & 48 & 18.2 \\
& University & 0 & 0 \\
\hline
\end{tabular}

Table 2. Pupils' physical complaints pertinent to the study at the time of data collection according to pupils' sex.

\begin{tabular}{lcc} 
Type of physical complaint & Male $(\mathbf{n}=93)$ & Female $(\mathbf{n}=\mathbf{1 7 1})$ \\
& $\mathrm{N} / \%$ & $\mathrm{~N} / \%$ \\
Diarrhea & $12(14.8)$ & $108(63.2)$ \\
Abdominal colic & $48(51.6)$ & $126(73.7)$ \\
\hline Mucous in stool & $24(25.8)$ & $0(0)$ \\
\hline
\end{tabular}

Table 3. Description of school's facilities and sanitary conditions of the study sample.

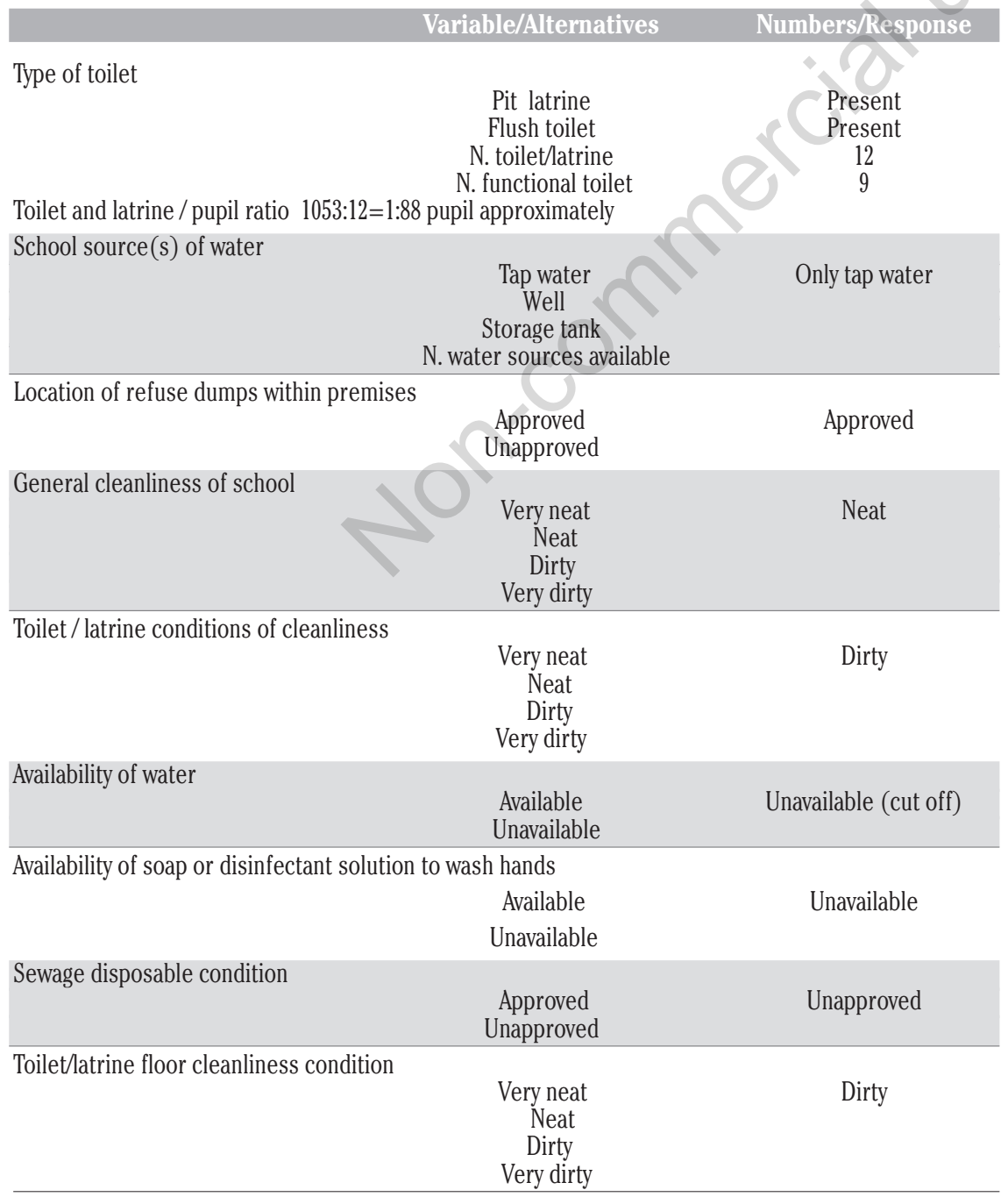

pupils were examined for ova, cysts and/or larvae of intestinal parasites using the direct wet mount and formal-ether concentration techniques. Inspection of sanitary facilities and conditions of hygiene of the school, as well as conditions of hygiene of the pupils, were carried out through observation checklists. The inventory of sanitary facilities within the school premises was also assessed through an observational checklist. Observation on site of the school premises was also conducted to ascertain the state of cleanliness of the school environment and sanitation at the time of data collection. These on site observations evaluated: toilet/latrine cleanliness and conditions, availability of water, availability of soap or disinfectant solution to wash hands, sewage disposal system, and cleanliness and condition of the floors. The observational checklist of the school was applied three times randomly over the period of data collection. The observational checklist of the conditions of hygiene of the pupils included: observation of general hygiene and grooming, condition and cleanliness of hands and finger nails, and hand washing after defecations, as well as the sharing of underwear with other siblings. Data were collected, coded and analyzed using a descriptive statistical method, in addition to measures of association; Eta2 aided with the computer based Statistical Package for Social Sciences (SPSS).

\section{Results}

Table 1 shows the socio-demographic data of the study sample. Out of 264 randomly selected pupils, 93 were males and 171 females. Age ranged from six to 12 years and more than three-quarters of the pupils were aged 9-12 years $(76.1 \%$ of pupils), with a mean score of $8.85 \pm 1.18$. The majority of the pupils' parents were illiterate $(72.7 \%$ of fathers and $81.8 \%$ of mothers). Also, the majority of pupils' parents were manual workers $(80.3 \%$ of fathers and $90.9 \%$ of mothers).

Table 2 shows the physical complaints pertinent to the study presented by the pupils at the time of data collection according to pupils' sex. Findings show the presence of some pertinent physical complaints among both males and females. One of the complaints was diarrhea which was presented by $14.8 \%$ and $63.2 \%$ of males and females, respectively, while abdominal colic was presented by $51.6 \%$ and $73.7 \%$ of males and females, respectively. Mucous in the stool was observed in only $25.8 \%$ of male pupils. None of the pupils in the present study suffered from blood in the urine, blood in the stool or fever.

Table 3 describes the facilities and sanitary conditions of the school. Twelve pit latrines 
and flush toilets were found on the school premises; 9 of them were functioning and the toilet and latrine to pupil ratio was 1:88 approximately. The only source of water at the school was tap water. The location of refuse dumps within the school premises corresponded to that approved. As far as the general cleanliness of school is concerned, the school was neat. Meanwhile, the toilets and latrines were found to be dirty and there was no water; this had been cut off. Also there was no soap or disinfectant solution available. The facilities for sewage disposal had, therefore, not been approved and the floor of the toilets and latrines was dirty.

Table 4 shows pupils' conditions of hygiene according to the pupils' sex. The findings showed that less than half of male and female pupils met the approved standards of general conditions of hygiene and personal grooming ( $43 \%$ and $40.9 \%$, respectively). Only $12.9 \%$ and $42.1 \%$ of male and female pupils, respectively, were in the habit of washing vegetables by themselves. Only a minority kept their hands and the nail bed clean. None of the pupils washed their hands after defecation for the sample. Most of them shared underwear with their siblings.

Five intestinal parasites were found among the study sample; percentages differed between male and female pupils (Table 5). Entamoeba coli accounted for $19.3 \%$ of pupils; $22.6 \%$ of males and $11.7 \%$ of females. Ascaris lumbricoides accounted for $3.8 \%$ of pupils; $3.2 \%$ of males and $4.1 \%$ of females. Hymenolepis nana was recorded in $12.5 \%$ of pupils; $11.8 \%$ of males and $1.3 \%$ of females. Enterobious vermicularis was observed in $5.7 \%$ of the fecal samples examined; $4.3 \%$ of males and $6.4 \%$ of females. Giardia lamblia was found in $12.5 \%$ of the fecal samples examined; $15.1 \%$ of males and $11.1 \%$ of females. A highly significant statistical association between pupil sex and type of parasite was found $(\mathrm{P}<0.001)$.

\section{Discussion}

This study identified the prevalence of intestinal parasitic infections (19.3\%, 3.8\% 12.5\%, 5.7\% and 12.5\%) for Entamoeb coli, Ascaries lumbricoides, Hymenolepiasis nana, Enterobious vermicularis and Gairdia lambia, respectively, in school pupils. These findings were in line with similar studies conducted in Nigeria. The reasons for this prevalence may

Table 4. Distribution of pupils' conditions of hygiene according to sex $(n=264)$.

\begin{tabular}{|c|c|c|c|c|}
\hline \multirow[t]{2}{*}{ Variables } & \multirow{2}{*}{\multicolumn{2}{|c|}{ Male }} & \multicolumn{2}{|c|}{ Female } \\
\hline & & & N. & $\%$ \\
\hline \multicolumn{5}{|l|}{ General hygiene / grooming } \\
\hline Approved & 40 & 0 & 70 & 40.9 \\
\hline Unapproved & 53 & 57 & 101 & 59.1 \\
\hline \multicolumn{5}{|l|}{ Wash vegetables by herself/himself } \\
\hline Yes & 12 & 12.9 & 72 & 42.1 \\
\hline No & 81 & 87.1 & 99 & 57.9 \\
\hline \multicolumn{5}{|l|}{ Cleanliness of hands and nail beds } \\
\hline Clean & 24 & 25.8 & 24 & 14 \\
\hline Unclean & 69 & 74.2 & 147 & 86 \\
\hline \multicolumn{5}{|c|}{ Hands washed after defecation for the sample } \\
\hline $\begin{array}{ll}\text { Yes } \\
\text { No }\end{array}$ & 0 & 0 & 0 & 0 \\
\hline \multicolumn{5}{|l|}{ Share underwear with other siblings } \\
\hline Yes & 69 & 74.2 & 138 & 80.7 \\
\hline No & 24 & 25.8 & 33 & 19.3 \\
\hline
\end{tabular}

Table 5. Prevalence of intestinal parasitic infections according to pupils' sex (total $n=264$ ).

\begin{tabular}{lccccccc} 
Variables & \multicolumn{2}{c}{$\begin{array}{c}\text { Male } \\
(\mathrm{n}=93)\end{array}$} & \multicolumn{2}{c}{$\begin{array}{c}\text { Female } \\
(\mathrm{n}=171)\end{array}$} & \multicolumn{2}{c}{$\begin{array}{c}\text { Total both } \\
\text { sexes }\end{array}$} & $\begin{array}{c}\text { Measures of } \\
\text { association } \\
\text { Eta }^{2}\end{array}$ \\
& N. & $\%$ & N. & $\%$ & N. & $\%$ & 0.004 \\
Entamoeb coli & 21 & 22.6 & 20 & 11.7 & 51 & 19.3 & 0.000 \\
Ascaries lumbricoides & 3 & 3.2 & 7 & 4.1 & 10 & 3.8 & 0.000 \\
\hline Hymenolepiasis nana & 11 & 11.8 & 22 & 1.3 & 33 & 12.5 & 0.002 \\
Enterobious vermicularis & 4 & 4.3 & 11 & 6.4 & 15 & 5.7 & 0.003 \\
\hline Gairdia lambia & 14 & 15. & 19 & 11.1 & 33 & 12.5 & \\
\hline
\end{tabular}

*Highly significant statistical association.

be attributed to poor environmental conditions and personal hygiene, an inadequate supply of drinking water, and a waste disposal system which does not correspond to approved standards. ${ }^{10-12}$ There was a highly statistical association between pupil sex and type of parasite in the present study. Authors recorded higher infection rates in males and reasoned that this was a result of gender differences in recreational activities. ${ }^{13-15}$

The study observed that sanitary facilities in the school were inadequate and this is of epidemiological significance considering the number of hours pupils spend in school. The ratio of the number of pupils per toilet far exceeds that recommended. ${ }^{12}$ Furthermore, the lack of available water within the school premises, combined with the factors discussed above, exacerbated the risk of infection. This widespread contamination of the school environment with pathogenic organisms underscores the importance of correct and appropriate disposal of waste in the protection and promotion of sustainable health. The provision of adequate sanitary facilities in school could interrupt transmission of fecal-oral pathogens. Epidemiological evidence suggests that improvement of sanitation and community hygiene, along with improvements in water supply, have a considerable impact in reducing communicable diseases. ${ }^{16,17}$ The absence of drinking water in schools may drive pupils to other unhygienic sources, thereby increasing risk. The school environment offers an ideal terrain for intervention activities aimed at controlling intestinal parasitic diseases and elimination of potential risks. Provision of adequate toilet facilities that children are trained to use and are happy to use will certainly discourage indiscriminate defecation elsewhere. The outcome of this study underscores the urgent need for provision and improvement of sanitary facilities in schools. Consistent intervention strategies should be targeted at the parasites by way of environmental sanitation through provision of sanitary facilities and adherence to personal hygiene ethics through health education. ${ }^{18,19}$

These will go a long way in reducing the scourge of intestinal parasitic infections in pupils. The involvement of parents and other stakeholders in designing and implementing these interventions is fundamental to their success.

\section{References}

1. Ekpenyong E. Prevalence of intestinal helminths infections among schooling children in Tropical Semi Urban Communities. Anim Res Int 2008;5:804-10. 2. Jamaiah I, Rohela M. Prevalence of intes- 
tinal parasites among members of the Public in Kuala Lumpur, Malaysia. Southeast Asian J Trop Med Public Health 200;36:68-71.

3. Bdir S, Adwan. G. Prevalence of intestinal parasitic infections in Jenin Governorate, Palestine: a 10-year retrospective study. Asian Pac J Trop Med 2010;745-7.

4. Luong TV. De-worming school children and hygiene intervention. Int J Environ Health Res 2003;13:S153-9.

5. Mehraj V, Hatcher J, Akhtar S, Rafique G, Asim M. Prevalence and factors associated with intestinal parasitic infection among children in an Urban Slum of Karachi. PLoS ONE 2010;3:e3680.

6. Sharma BK, Rai SK, Diyo Ram Rai DR, Choudhury DD. Prevalence of Intestinal Parasitic Infestation in Schoolchildren in the Northeastern Part of Kathmandu Valley, Nepal. Southeast Asian J Trop Med Public Health 2004;35:501-5.

7. Nematian J, Gholamrezanezhad A, Nematian E. Giardiasis and other intestinal parasitic infections in relation to anthropometric indicators of malnutrition: a large, population-based survey of schoolchildren in Tehran. Ann Trop Med Parasitol 2008;102:209-14.

8. World Health Organization (WHO).
Controlling disease due to helminth infections. 2003, Geneva, Switzerland. Available from: www.who.int

9. Ahmed AK, Malik B, Shaheen B, et al. Frequency of intestinal parasitic infestation in children of 5-12 years of age in Abbottabad. J Ayub Med Coll Abbottabad 2003;15:28-30.

10. Adeyeba OA, Akinlabi AM. Intestinal Parasitic infection among school children in a rural community, southwest Nigeria. Nigerian J Parasitol 2002;23:11-8.

11. Ukpai OM, Ugwu CD. The prevalence of gastro-intestinal tract parasites in primary school children in Ikwuano LGA of Abia State, Nigeria. Nigerian $\mathrm{J}$ Parasitol 2003;24:129-36.

12. Banke ROK, Omudu EA, Ikenwa DA and Feese IJ. Prevalence of gastro-intestinal parasites in relation to availability of sanitary facilities among schooling children in makurdi, Nigeria. Animal Research International. 2006;3(2):489-93.

13. Aly NSM, Mostafa MM. Intestinal parasitic infection among children in the Kingdom of Saudi Arabia. Aust J Basic Appl Sci 2010;4:4200-4.

14. Cauyan GA, Andaman DE, Maricar SM, et al. Prevalence of intestinal parasites among schoolchildren in a Coastal Rural
Area of Maragondon, Cavite, Southern Luzon, Philippines. Acta Manilana 2008;56:43-9.

15. Ulukanligil M, Seyrek A. Demographic and parasitic infection status of schoolchildren and sanitary conditions of schools in Sanliurfa, Turkey. BMC Public Health 2003;3:29.

16. Graczyk TK, Shiff CK, Tamang L, et al. The association of Blastocystis hominis and Endolimax nana with diarrheal stools in Zambian school-age children. Parasitol Res 2005;98:38-43.

17. Minvielle MC, Pezzani BC, Cordoba MA, et al. Epidemiological survey of Giardia spp. and Blastocystis hominis in an Argentinian rural community. Korean J Parasitol 2004;42:121-7.

18. Jiraamonninit C, Wongkamchai S, Santabutr W, et al. The Prevalence of intestinal parasitic infections among schoolchildren with annual anthelminthic treatment in Narathiwat Province, Thailand. J Trop Med Parasitol 2006;29:4550.

19. Awolaju BA, Morenikeji OA. Prevalence and intensity of intestinal parasites in five communities in south-west Nigeria. Afr J Biotechnol 2009;8:4542-6. 